\title{
26454 - PREOP EMOTIONAL NUMBING PREDICTS IMPROVEMENT IN PAIN DISABILITY 6 MO LATER
}

\section{Joel Katz PhD, Maria Dzyuba, MD; Eileen Halket, RN; Andrea Martin, Gordon GJ Asmundson, PhD; Toronto General Hospital, Toronto, ON, Canada}

INTRODUCTION: Recent epidemiological research points to an alarmingly high rate of chronic postsurgical pain (CPSP). As well, almost 25\% of patients who attend chronic pain clinics are referred because of CPSP. The role of psychosocial factors in the development of CPSP remains a neglected and understudied area.

AIM: To predict pain disability 6 months after surgery from preoperative posttraumatic stress symptoms (PTSS), such as emotional numbing.

METHODS: Patients who were to receive iv PCA or PCA-E after surgery were eligible to participate. One week before surgery, patients completed validated questionnaires assessing pain disability, pain-related anxiety and fear, pain catastrophizing, and PTSS (Table). Twenty-four and 48 hours after surgery, pain intensity and total morphine consumption were recorded. Six months after surgery, patients were telephoned to determine CPSP incidence, pain disability, and PTSS.

RESULTS: Thirty-nine (13 male, 26 female) of 140 (27.9\%) patients reported CPSP 6 months after surgery. Data were analyzed using a 4-step multiple regression analysis (Table). The primary outcome measure was the change in pain disability index (PDI) scores from the preoperative assessment to the 6 month follow up. After controlling for pre-operative psychosocial variables (Step 1), acute postoperative biomedical variables (Step 2) and 6 month posttraumatic emotional numbing scores (Step 3), preoperative posttraumatic emotional numbing made a significant, independent contribution $\left(\mathrm{R}^{2}=\right.$ $0.13)$ to the prediction of pain disability change scores $(\mathrm{p}<0.00009)$.

DISCUSSION: Increased emotional numbing before surgery was associated with improvements (i.e., greater decreases) in pain disability change scores six months after surgery. It is possible that heightened emotional numbing prior to surgery is protective against subsequent increases in pain disability. The source of the preoperative emotional numbing is not known but it may result from a diagnosis of cancer, the prospect of surgery, or some unrelated earlier trauma. Further research is needed to determine the role (if any) of the endogenous opioid system in mediating this effect. 


\begin{tabular}{|c|c|c|c|c|c|}
\hline Step & $\begin{array}{l}\text { Variables in Multiple Regression Analysis } \\
\text { Predicting Change in Pain Disability Scores }\end{array}$ & $\begin{array}{l}\text { Total } \\
\mathrm{R}^{2}\end{array}$ & $\begin{array}{c}\mathrm{R}^{2} \\
\text { Change }\end{array}$ & $\begin{array}{c}\text { F } \\
\text { Change }\end{array}$ & Beta \\
\hline 1 & \begin{tabular}{|l|} 
Preoperative psychosocial measures \\
ASI - Anxiety sensitivity index \\
PCS - Pain catastrophizing scale \\
PASS-20 - Pain anxiety symptoms \\
FPQ - Fear of pain questionnaire \\
STAI - Spielberger state anxiety \\
MOS-SSS - Social support survey \\
\end{tabular} & 0.05 & 0.05 & 0.93 & $\begin{array}{r}-0.04 \\
-0.19 \\
-0.06 \\
0.10 \\
0.30 \\
-0.01 \\
\end{array}$ \\
\hline 2 & $\begin{array}{l}\text { Acute postop biomedical measures } \\
\text { Type of surgery } \\
\text { Pain - Days } 1 \text { and } 2 \text { pain ratings } \\
\text { Total PCA morphine (mg) }\end{array}$ & 0.09 & 0.04 & 1.46 & $\begin{array}{r}-0.01 \\
0.02 \\
-0.22 \\
\end{array}$ \\
\hline 3 & $\begin{array}{l}6 \text { month follow up emotional munbing } \\
\text { PTSD checklist emotional numbing } \\
\text { subscale }\end{array}$ & 0.26 & 0.17 & $22.1^{*}$ & $0.45^{*}$ \\
\hline 4 & $\begin{array}{l}\text { Preoperative emotional numbing } \\
\text { PTSD checklist emotional numbing } \\
\text { subscale }\end{array}$ & 0.40 & 0.13 & $20.9^{*}$ & $-0.48^{*}$ \\
\hline
\end{tabular}

